\title{
Natural constructal emergence of vascular design with turbulent flow
}

\author{
E. Cetkin, ${ }^{1}$ S. Lorente, ${ }^{2}$ and A. Bejan ${ }^{1, a)}$ \\ ${ }^{1}$ Department of Mechanical Engineering and Materials Science, Duke University, Durham, \\ North Carolina 27708-0300, USA \\ ${ }^{2}$ Laboratoire Matériaux et Durabilité des Constructions (LMDC), UPS, INSA, Université de Toulouse, 135, \\ Avenue de Rangueil, F-31 077 Toulouse Cedex 04, France
}

(Received 18 March 2010; accepted 6 April 2010; published online 1 June 2010)

\begin{abstract}
Here, we show that vascular design emerges naturally when a volume is bathed by a single stream in turbulent flow. The stream enters the volume, spreads itself to bathe the volume, and then reconstitutes itself as a single stream before it exits the volume. We show that in the pursuit of a smaller global flow resistance and larger volumes, the flow architecture changes stepwise from a stack of identical elements bathed in parallel flow (like a deck of cards) to progressively more complex structures configured as trees matched canopy to canopy. The transition from one architecture to the next occurs at a precise volume size, which is identified. Each transition marks a decrease in the rate at which the global flow resistance increases with the volume size. This decrease accelerates as the volume size increases. The emergence of such vasculatures for turbulent flow is compared with the corresponding phenomenon when the flow is laminar. To predict this design generation phenomenon is essential to being able to scale up the designs of complex flow structures, from small scale models to life size models. The constructal law is a bridge between the principles of physics and biology. (C) 2010 American Institute of Physics. [doi:10.1063/1.3430941]
\end{abstract}

\section{INTRODUCTION}

The phenomenon of design generation and evolution in the nature and engineering is described by the constructal law. ${ }^{1,2}$ Flow architectures change in time so that they provide easier flow access than existing configurations. The current literature shows that there are many applications of this principle, in the diverse areas such as biology, geophysics, engineering, and microscales and macroscales. ${ }^{1-31}$

According to constructal theory, the designing and assembling of microscale and nanoscale components into macroscopic devices can be achieved by using the vascular flow structures that are distributed throughout the working volume. Vascularization can be viewed as the technology that moves the microtechnologies and nanotechnologies from laboratory to practice, which is to actual, palpable devices. Furthermore, vascular smart materials promise new capabilities, such as self-healing and self-cooling, which are due to their ability to bathe volumetrically their solid bodies. Constructal theory serves the vascularization revolution because tree-shaped flow architectures provide effective pointvolume flow access. ${ }^{1}$

In this paper we show how vascular designs should be configured when the flow in all the channels is turbulent. We also show how these designs must change when the size of the vascular body changes.

\section{TAPERED DUCTS}

We begin with the question of how to shape one channel so that discharges fluid uniformly along its length. The

\footnotetext{
${ }^{a)}$ Author to whom correspondence should be addressed. Electronic mail: abejan@duke.edu.
}

uniform discharge is a model of the two horizontal ducts in the design shown in Fig. 1, where every elemental volume $\mathrm{d} \times \mathrm{H} \times \mathrm{y}$ receives the same vertical stream $\dot{\mathrm{m}}_{\mathrm{e}}$. The upper horizontal duct is shown in Fig. 2. Because of the uniform lateral flow, the flow rate in the horizontal duct varies linearly $\dot{m}(\mathrm{x})=\dot{\mathrm{m} x} / \mathrm{L}$. The pressure drop for turbulent flow becomes

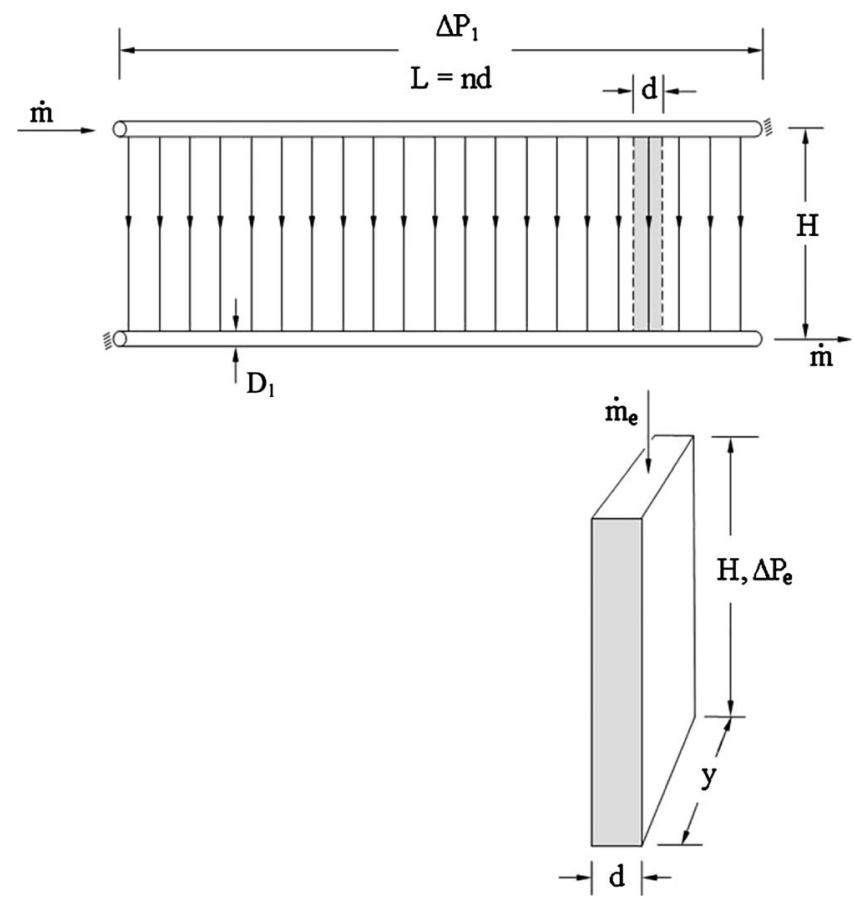

FIG. 1. Stack of $\mathrm{n}$ elemental flow volumes in a volume bathed by a single stream. 

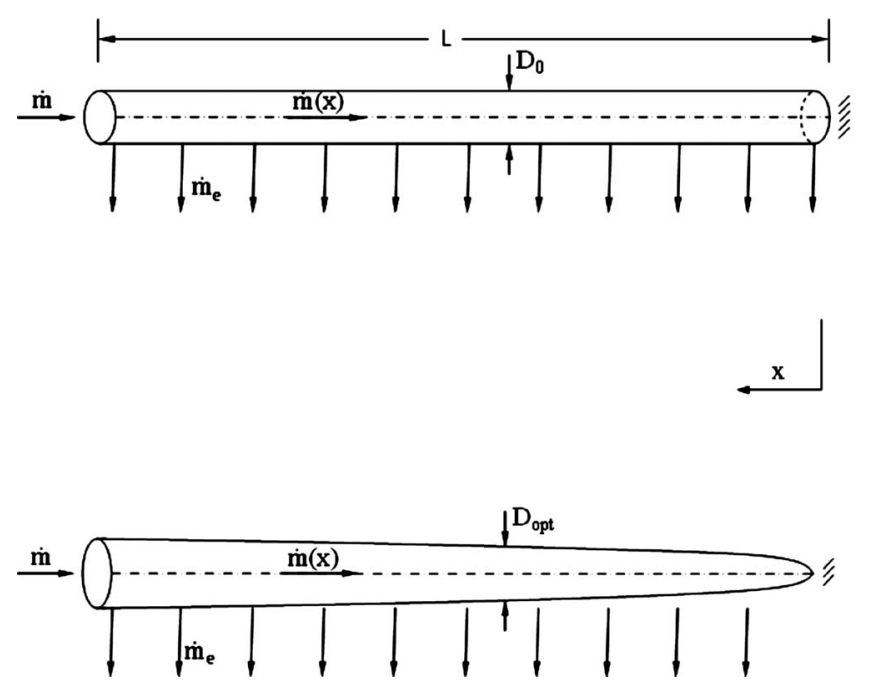

FIG. 2. Supply duct with longitudinally distributed discharge: tube with constant diameter (top) and tapered tube (bottom).

$$
\Delta \mathrm{P}=\mathrm{C}_{\mathrm{t}} \frac{\dot{\mathrm{m}}^{2}}{\mathrm{~L}^{2}} \int_{0}^{\mathrm{L}} \frac{\mathrm{x}^{2}}{\mathrm{D}^{5}} \mathrm{dx},
$$

where $\mathrm{C}_{\mathrm{t}}=32 \mathrm{f} / \pi^{2} \rho$, and $\mathrm{f}$ is the constant friction factor for turbulent flow in the fully developed and fully rough regime. ${ }^{1}$ The volume constraint is

$$
\mathrm{V}=\int_{0}^{\mathrm{L}} \frac{\pi}{4} \mathrm{D}^{2} \mathrm{dx},
$$

where, $\dot{\mathrm{m}}, \mathrm{L}, \mathrm{x}$, and $\mathrm{D}$ are the mass flow rate that enters the duct, the length, the distance from the closed end of the duct, and the diameter, respectively, Fig. 2. The pressure drop along the duct with constant diameter is

$$
\Delta \mathrm{P}_{0}=\mathrm{C}_{\mathrm{t}} \frac{\dot{\mathrm{m}}^{2} \mathrm{~L}}{3 \mathrm{D}_{0}^{5}},
$$

Next, consider the general case where the duct shape $\mathrm{D}(\mathrm{x})$ is free to vary. By using variational calculus we minimized the $\Delta \mathrm{P}$ integral Eq. (1) subject to the constraint Eq. (2), and found the optimally tapered channel and the minimum pressure drop,

$$
\begin{aligned}
& \mathrm{D}_{\mathrm{opt}}=\left(\frac{44 \mathrm{~V}}{7 \pi \mathrm{L}^{11 / 7}}\right)^{1 / 2} \mathrm{x}^{2 / 7}, \\
& \Delta \mathrm{P}_{\min }=\mathrm{C}_{\mathrm{t}} \frac{7^{7 / 2} \dot{\mathrm{m}}^{2} \pi^{5 / 2} \mathrm{~L}^{7 / 2}}{11^{7 / 2}(4 \mathrm{~V})^{7 / 2}} .
\end{aligned}
$$

Dividing Eq. (5) by Eq. (3) we see that the tapering of the duct yields a $38 \%$ reduction in overall flow resistance.

$$
\frac{\Delta \mathrm{P}_{\min }}{\Delta \mathrm{P}_{0}}=3\left(\frac{7}{11}\right)^{7 / 2}=0.62 \text {. }
$$

This is an attractive feature but it does not always yield a uniform $\dot{m}_{\mathrm{e}}$ in a design with two tapered tubes sharing the same lateral discharge (Fig. 1). The reason is that when D varies as $\mathrm{x}^{2 / 7}$ the pressure gradient along the duct $(\mathrm{dP} / \mathrm{dx})$ varies as $x^{4 / 7}$, i.e., it is not constant. The pressure gradient is steeper near the entrance to the upper horizontal duct, and shallower near the closed end. Along the lower duct, the pressure gradient is shallower near the left end and steeper near the right end. An assembly of two optimally tapered tubes would impose a greater pressure difference on the elemental $\left(\dot{m}_{\mathrm{e}}\right)$ channels situated near the left and right ends of the assembly. The $\dot{\mathrm{m}}_{\mathrm{e}}$ channels near the mid plane $(\mathrm{x}=\mathrm{L} / 2)$ would be subjected to a smaller pressure difference in the vertical direction, and this means that the elemental flow rate $\dot{\mathrm{m}}_{\mathrm{e}}$ will be distributed nonuniformly from $\mathrm{x}=0$ to $\mathrm{x}=\mathrm{L}$. This would contradict the constant- $\dot{\mathrm{m}}_{\mathrm{e}}$ assumption with which the present analysis started.

The constant- $\dot{\mathrm{m}}_{\mathrm{e}}$ design can be implemented by designing the upper and lower ducts such that $\mathrm{dP} / \mathrm{dx}$ is the same constant for each. According to Eq. (1), this means that $x^{2} / D^{5}$ must be independent of $x$, and this yields a duct tapered as $\mathrm{D} \sim \mathrm{x}^{2 / 5}$. Repeating the preceding analysis we find the geometry and the performance of the constant- $\mathrm{dP} / \mathrm{dx}$ design,

$$
\begin{aligned}
& \mathrm{D}_{\mathrm{c}}=\left(\frac{36 \mathrm{~V}}{5 \pi \mathrm{L}^{9 / 5}}\right)^{1 / 2} \mathrm{x}^{2 / 5}, \\
& \Delta \mathrm{P}_{\mathrm{c}}=\mathrm{C}_{\mathrm{t}} \frac{\dot{\mathrm{m}}^{2}(5 \pi)^{5 / 2} \mathrm{~L}^{7 / 2}}{(36 \mathrm{~V})^{5 / 2}} .
\end{aligned}
$$

Dividing Eq. (8) by Eq. (3) we learn that the constant-dP/dx design performs almost as well as the optimally shaped duct,

$$
\frac{\Delta \mathrm{P}_{\min }}{\Delta \mathrm{P}_{0}}=3\left(\frac{5}{9}\right)^{5 / 2}=0.69
$$

In summary, the tapering of the ducts has a relatively small effect on the flow resistance of the upper and lower channels in Fig. 1. The $\Delta \mathrm{P}$ of each channel is represented well by the $\Delta \mathrm{P}_{0}$ scale reported in Eq. (3). For the sake of simplicity, we proceed based on the assumption that the horizontal channels have constant diameter, the pressure difference is estimated in Eq. (3), and the lateral distribution of flow discharge $(\mathrm{dm} / \mathrm{dx})$ is nearly uniform. This last assumption is valid when the elemental flow resistance encountered by $\dot{\mathrm{m}}_{\mathrm{e}}$ inside the $\mathrm{d} \times \mathrm{H} \times \mathrm{y}$ volume is high enough so that the pressure difference along the $\dot{\mathrm{m}}_{\mathrm{e}}$ channel is comparable with or greater than the pressure difference along the horizontal channel.

\section{FIRST CONSTRUCT}

Consider now the stack of elemental volumes, Fig. 1. The stream m flows as two trees matched canopy to canopy. The first tree flow distributes the $\dot{m}$ stream over the entire available volume. The second tree reconstitutes the m stream and leads it out of the volume.

Many parallel channels are supplied by two horizontal channels (diameter $\mathrm{D}_{1}$ ), one along the top and the other along the bottom. The stack of $n$ elements of size $\mathrm{d} \times \mathrm{H} \times \mathrm{y}$ fills a volume of length $\mathrm{L}=\mathrm{nd}$, height $\mathrm{H}$, and thickness $\mathrm{y}$, which is perpendicular to the plane of Fig. 1. The flow rate m through the stack is steady and known. The pressure drop along the supply duct of Fig. 1 is the $\Delta \mathrm{P}_{0}$ expression of Eq. (3). The total pressure drop along the supply and discharge ducts is $\Delta \mathrm{P}_{1}=2 \Delta \mathrm{P}_{0}$, 


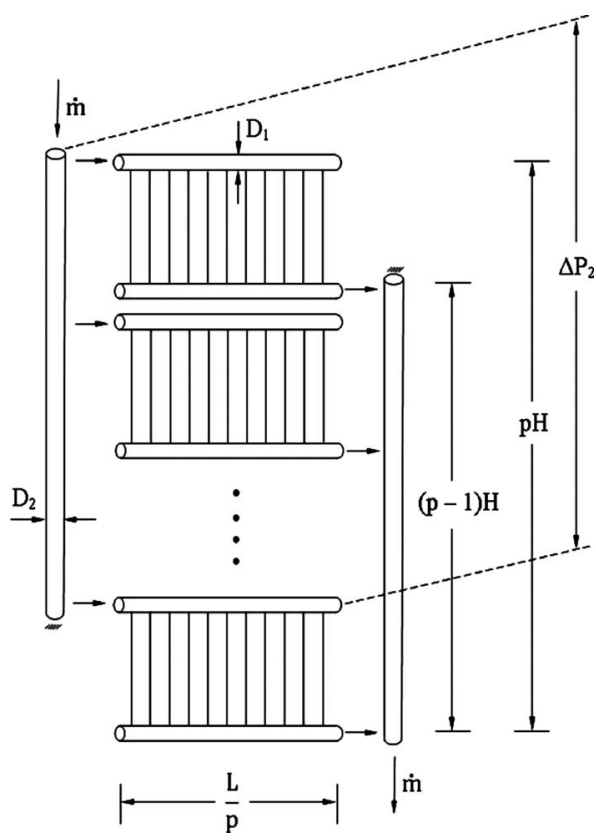

FIG. 3. Stack of $\mathrm{p}$ assemblies, each containing of $\mathrm{n} / \mathrm{p}$ elemental volumes.

$$
\Delta \mathrm{P}_{1}=\frac{2}{3} \mathrm{C}_{\mathrm{t}} \dot{\mathrm{m}}^{2} \frac{\mathrm{L}}{\mathrm{D}_{1}^{5}}
$$

The total volume of the two ducts is

$$
\mathrm{V}=2 \frac{\pi}{4} \mathrm{D}_{1}^{2} \mathrm{~L}
$$

Combining Eqs. (10) and (11) to eliminate $\mathrm{D}_{1}$, we obtain

$$
\Delta \mathrm{P}_{1}=\frac{2}{3} \mathrm{C}_{\mathrm{t}} \dot{\mathrm{m}}^{2} \mathrm{~L}\left(\frac{\pi \mathrm{L}}{2 \mathrm{~V}}\right)^{5 / 2} \text {. }
$$

\section{SECOND CONSTRUCT}

Consider next the question of whether it is beneficial to configure the stack in a way that is markedly different than in Fig. 1. A two-dimensional alternative is shown in Fig. 3, which is the result of cutting the stack of Fig. 1 into p equal pieces, and stacking these pieces in the vertical direction. This new design has a two-dimensional pattern with the vertical dimension $\mathrm{pH}$ and the horizontal dimension $\mathrm{L} / \mathrm{p}$. The flow is distributed by $\mathrm{p}$ horizontal channels of length $\mathrm{L} / \mathrm{p}$ and diameter $\mathrm{D}_{1}$ and a vertical channel of height $(\mathrm{p}-1) \mathrm{H}$ and diameter $\mathrm{D}_{2}$. The flow from one corner of this assembly to the diagonally opposed corner is steady.

To compare Figs. 1 and 3 analytically and on the same basis, we assume that the configuration and flow needs of a single $\mathrm{d} \times \mathrm{H} \times \mathrm{y}$ element are fixed. This means that $\mathrm{H}, \mathrm{d}$, $\dot{\mathrm{m}}_{\mathrm{e}}=\dot{\mathrm{m}} / \mathrm{n}$, and the diameter of the thin channel that runs along the centerline of the element are fixed. Therefore, the pressure drop $\Delta \mathrm{P}_{\mathrm{e}}$ from one end of the $\mathrm{d} \times \mathrm{H} \times \mathrm{y}$ element to the other end is fixed.

Assume that $\mathrm{p}$ and $\mathrm{n}$ are sufficiently greater than 1 so that the pressure drop for a channel with turbulent flow is as in Eq. (3),

$$
\Delta \mathrm{P}_{\mathrm{i}}=\frac{1}{3} \mathrm{C}_{\mathrm{t}} \dot{\mathrm{m}}_{\mathrm{i}}^{2} \frac{\mathrm{L}_{\mathrm{i}}}{\mathrm{D}_{\mathrm{i}}^{5}}
$$

The pressure drop along the distributing and collecting ducts in Fig. 3 has two parts such as: the pressure drop along two ducts of diameter $\mathrm{D}_{2}$ and length $(\mathrm{p}-1) \mathrm{H}$ and two ducts of diameter $\mathrm{D}_{1}$ and length $\mathrm{L} / \mathrm{p}$,

$$
\Delta \mathrm{P}_{2}=\frac{2}{3} \mathrm{C}_{\mathrm{t}} \dot{\mathrm{m}}^{2} \frac{(\mathrm{p}-1) \mathrm{H}}{\mathrm{D}_{2}^{5}}+\frac{2}{3} \mathrm{C}_{\mathrm{t}} \frac{\dot{\mathrm{m}}^{2}}{\mathrm{p}^{2}} \frac{\mathrm{L} / \mathrm{p}}{\mathrm{D}_{1}^{5}} \text {. }
$$

The flow rate through the $\mathrm{D}_{1}$ duct is $\dot{\mathrm{m}} / \mathrm{p}$, and it appears as $\dot{\mathrm{m}}^{2} / \mathrm{p}^{2}$ in Eq. (14) because in turbulent flow the pressure drop is proportional to $\dot{\mathrm{m}}^{2}$. The total tube volume of the Fig. 3 is occupied by the distributing and collecting ducts,

$$
\mathrm{V}=2 \frac{\pi}{4} \mathrm{D}_{2}^{2}(\mathrm{p}-1) \mathrm{H}+2 \mathrm{p} \frac{\pi}{4} \mathrm{D}_{1}^{2} \frac{\mathrm{L}}{\mathrm{p}}
$$

The total space occupied by the first and second constructs (Figs. 1 and 3) is the same, $(\mathrm{pH}) \times(\mathrm{L} / \mathrm{p})=\mathrm{LH}$. The ratio $D_{2} / D_{1}$ is the only degree of freedom in the minimization of the pressure drop. By minimizing $\Delta \mathrm{P}_{2}$ with respect to the $\mathrm{D}_{2} / \mathrm{D}_{1}$ subject to constraint (15), we find

$$
\frac{\mathrm{D}_{2}}{\mathrm{D}_{1}}=\mathrm{p}^{3 / 7}
$$

The minimized pressure drop for the second construct is

$$
\Delta \mathrm{P}_{2}=\frac{2}{3} \mathrm{C}_{\mathrm{t}} \frac{\dot{\mathrm{m}}^{2} \mathrm{~L}^{7 / 2}}{\mathrm{p}^{3} \mathrm{~V}^{5 / 2}}\left(\frac{\pi}{2}\right)^{5 / 2}\left[\frac{\mathrm{H}}{\mathrm{L}}(\mathrm{p}-1) \mathrm{p}^{6 / 7}+1\right]^{7 / 2} \text {. }
$$

Dividing Eq. (17) by Eq. (12), we discover which construct offers less resistance, Fig. 1 or Fig. 3,

$$
\frac{\Delta \mathrm{P}_{2}}{\Delta \mathrm{P}_{1}}=\frac{1}{\mathrm{p}^{3}}\left[\frac{\mathrm{H}}{\mathrm{L}}(\mathrm{p}-1) \mathrm{p}^{6 / 7}+1\right]^{7 / 2} \text {. }
$$

This ratio is less than 1 when the number of elements $n$ is large enough so that

$$
\frac{1}{\mathrm{p}}>\frac{\mathrm{H}}{\mathrm{nd}} \frac{1-\mathrm{p}^{-1}}{1-\mathrm{p}^{-6 / 7}}
$$

When $\mathrm{p} \gg 1$, this criterion is nearly the same as $\mathrm{nd} / \mathrm{H} \geq \mathrm{p}$. When the inequality Eq. (19) holds, the second construct (Fig. 3) offers a smaller flow resistance than the first construct (Fig. 1). This is shown in Fig. 4. The reductions in flow resistance offered by the second construct (Fig. 3) are dramatic when the overall volume is large enough such that $\mathrm{nd} / \mathrm{H}>\mathrm{p}$. Furthermore, the pressure difference ratio between the second and the first construct becomes a constant after a limit such as $n d / p H=10$ when $\mathrm{p}=3$, Fig. 4 .

\section{THIRD CONSTRUCT}

An alternative to the two-dimensional second construct of Fig. 3 is the three-dimensional construct shown in Fig. 5. Here, the first-construct segments of length L/p are stacked in the direction perpendicular to the plane of Figs. 1 and 3. The thickness of the new structure is py because the thickness of the elemental volume is $y$, and the total volume consists of $\mathrm{p}$ pieces of size $\mathrm{H} \times(\mathrm{L} / \mathrm{p})$. The space occupied by 


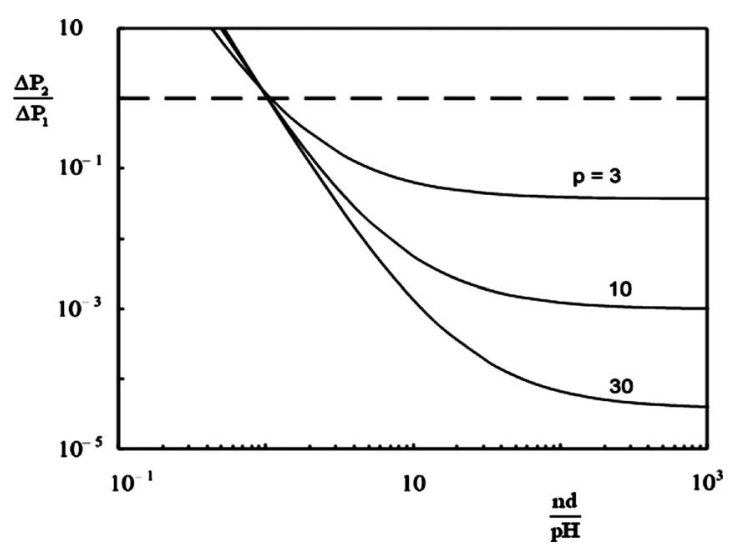

FIG. 4. The overall pressure drop of the second construct (Fig. 3) divided by the pressure drop of the first construct (Fig. 1). The value on the abscissa is proportional to the total volume of the assembly of elements.

the construct of Fig. 5 is the same as in Figs. 1 and 3, namely $\mathrm{H} \times$ py $\times \mathrm{L} / \mathrm{p}=\mathrm{LHy}$. The length of one of the distributing or collecting ducts of diameter $\mathrm{D}_{3}$ in Fig. 5 is $(\mathrm{p}-1) \mathrm{y}$. The overall pressure drop and volume constraint for the threedimensional construct are

$$
\begin{aligned}
& \Delta \mathrm{P}_{3}=\frac{2}{3} \mathrm{C}_{\mathrm{t}} \dot{\mathrm{m}}^{2} \frac{(\mathrm{p}-1) \mathrm{y}}{\mathrm{D}_{3}^{5}}+\frac{2}{3} \mathrm{C}_{\mathrm{t}} \frac{\dot{\mathrm{m}}^{2}}{\mathrm{p}^{2}} \frac{\mathrm{L} / \mathrm{p}}{\mathrm{D}_{1}^{5}}, \\
& \mathrm{~V}=2 \frac{\pi}{4} \mathrm{D}_{3}^{2}(\mathrm{p}-1) \mathrm{y}+2 \mathrm{p} \frac{\pi}{4} \mathrm{D}_{1}^{2} \frac{\mathrm{L}}{\mathrm{p}}
\end{aligned}
$$

The minimization of $\Delta \mathrm{P}_{3}$ with respect to $\mathrm{D}_{3} / \mathrm{D}_{1}$ subject to the constraint (21) yields

$$
\frac{D_{3}}{D_{1}}=p^{3 / 7}
$$

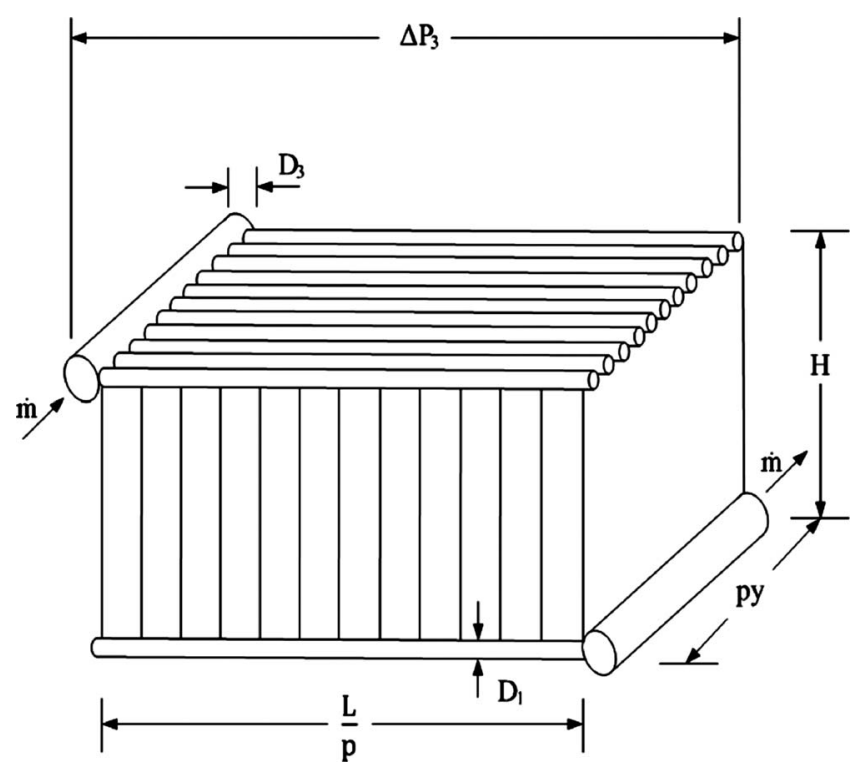

FIG. 5. Third construct: the p segments are stacked in the direction perpendicular to the plane of Fig. 3.

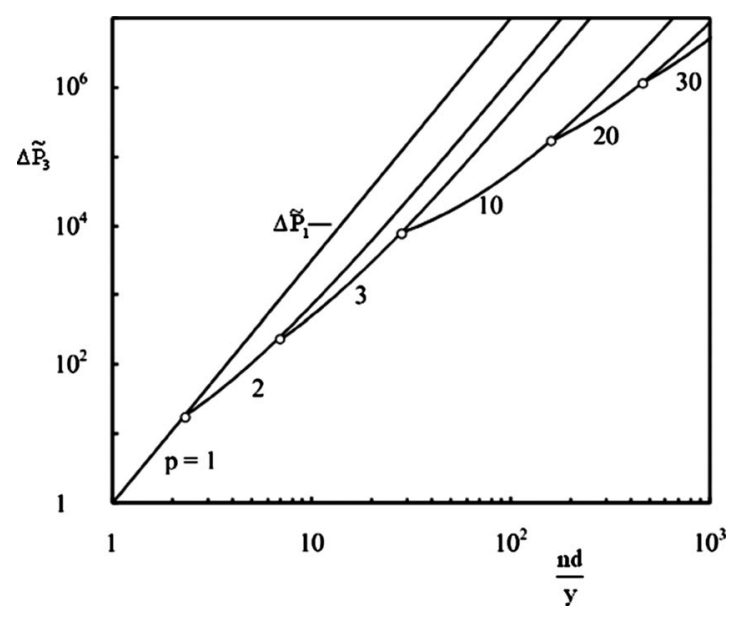

FIG. 6. The flow performance of the three-dimensional second construct of Fig. 5. Note the envelope of the constant-p curves.

$$
\Delta \mathrm{P}_{3}=\frac{2}{3} \mathrm{C}_{\mathrm{t}} \frac{\dot{\mathrm{m}}^{2} \mathrm{~L}^{7 / 2}}{\mathrm{p}^{3} \mathrm{~V}^{5 / 2}}\left(\frac{\pi}{2}\right)^{5 / 2}\left[\frac{\mathrm{y}}{\mathrm{nd}}(\mathrm{p}-1) \mathrm{p}^{6 / 7}+1\right]^{7 / 2} .
$$

Dividing Eqs. (23) and (17), we find the ratio of the global flow resistances of the constructs, the three-dimensional divided by the two-dimensional,

$$
\frac{\Delta \mathrm{P}_{3}}{\Delta \mathrm{P}_{2}}=\left[\frac{\frac{\mathrm{y}}{\mathrm{nd}}(\mathrm{p}-1) \mathrm{p}^{6 / 7}+1}{\frac{\mathrm{H}}{\mathrm{nd}}(\mathrm{p}-1) \mathrm{p}^{6 / 7}+1}\right]^{7 / 2} .
$$

This ratio becomes less than 1 when $\mathrm{y}<\mathrm{H}$. We can nondimensionalize the pressure drops by forming the flow resistance group

$$
\Delta \widetilde{\mathrm{P}}=\frac{\Delta \mathrm{PV}^{5 / 2}}{(2 / 3) \mathrm{C}_{\mathrm{t}} \dot{\mathrm{m}}^{2}(\pi / 2)^{5 / 2} \mathrm{y}^{7 / 2}} .
$$

The nondimensional pressure drops of the designs of Figs. 1 and 5 become

$$
\begin{aligned}
& \Delta \widetilde{\mathrm{P}}_{1}=\left(\frac{\mathrm{nd}}{\mathrm{y}}\right)^{7 / 2}, \\
& \Delta \widetilde{\mathrm{P}}_{3}=\frac{1}{\mathrm{p}^{3}}\left(\frac{\mathrm{nd}}{\mathrm{y}}\right)^{7 / 2}\left[\frac{\mathrm{y}}{\mathrm{nd}}(\mathrm{p}-1) \mathrm{p}^{6 / 7}+1\right]^{7 / 2} .
\end{aligned}
$$

Equation (26) is the $\mathrm{p}=1$ case of Eq. (27). This is shown in Fig. 6, where $\Delta \widetilde{\mathrm{P}}_{3}$ was plotted for various $\mathrm{n}$ and $\mathrm{p}$ values. Each constant-p curves starts from a point where $\Delta \tilde{\mathrm{P}}_{3}$ is lower than on the neighboring constant- $(\mathrm{p}-1)$ curve. The curves reveal an envelope of $\Delta \widetilde{\mathrm{P}}_{3}$ versus nd/y that falls significantly below the flow resistance of the first construct, $\Delta \widetilde{\mathrm{P}}_{1}$. If the total size of the volume is known (n), then the envelope of the $\Delta \widetilde{\mathrm{P}}_{3}$ curves can be used to determine the optimal number of segments (p) that must be used in the construction shown in Fig. 5.

The envelope of the $\Delta \widetilde{\mathrm{P}}_{3}$ curves in Fig. 6 can be determined analytically by writing $\Delta \widetilde{\mathrm{P}}_{3}(\mathrm{p})=\Delta \widetilde{\mathrm{P}}_{3}(\mathrm{p}+1)$. This con- 


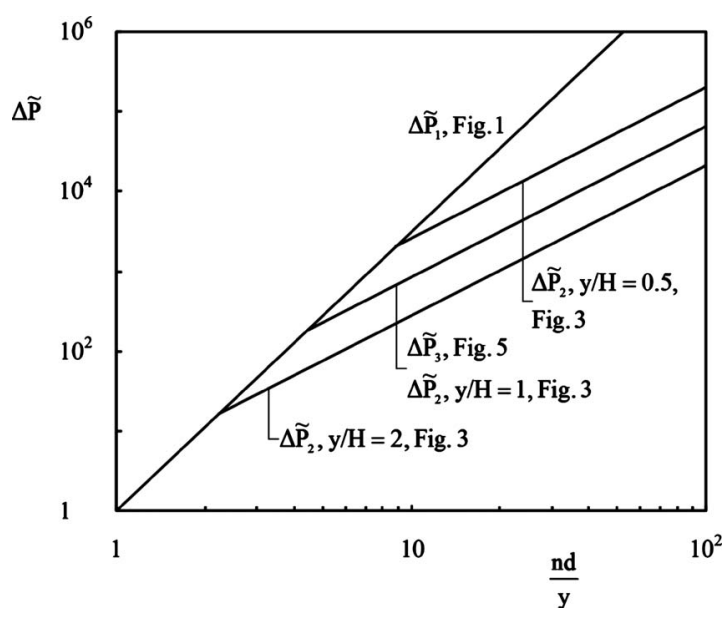

FIG. 7. Comparison between the global flow resistances offered by the constructs of Figs. 1, 3, and 5.

dition represents the point where we change our construct from $\mathrm{p}$ to $\mathrm{p}+1$ design. The transition and global performance are described by

$$
\begin{aligned}
& \frac{\mathrm{nd}}{\mathrm{y}}=\frac{1}{\mathrm{p}^{-6 / 7}-(\mathrm{p}+1)^{-6 / 7}}, \\
& \Delta \widetilde{\mathrm{P}}_{3}(\mathrm{p}, \mathrm{p}+1)=\left[\mathrm{p}+\frac{\mathrm{p}^{6 / 7}}{(\mathrm{p}+1)^{6 / 7}-\mathrm{p}^{6 / 7}}\right]^{7 / 2} .
\end{aligned}
$$

In the large-volume limit nd $\gg 1$, the $\mathrm{p}$ value is sufficiently greater than 1 so that Eqs. (28) and (29) approach

$$
\begin{aligned}
& \frac{\mathrm{nd}}{\mathrm{y}} \cong \frac{7}{6} \mathrm{p}^{13 / 7}, \\
& \Delta \widetilde{\mathrm{P}}_{3} \cong 11.12\left(\mathrm{n} \frac{\mathrm{d}}{\mathrm{y}}\right)^{49 / 26} .
\end{aligned}
$$

The advantage of configuring the stack as Fig. 5 relative to Fig. 1 is shown in Fig. 6, and it is significant. The pressure drop along the envelope of the constant-p curves increases as $\Delta \widetilde{\mathrm{P}}_{3} \sim(\mathrm{nd} / \mathrm{y})^{49 / 26}$, where $49 / 26=1.88$. This increase is considerably slower than in the design of Fig. 1 , where $\Delta \widetilde{\mathrm{P}}_{1}$ $\sim(\mathrm{nd} / \mathrm{y})^{7 / 2}$ and $7 / 2=3.5$. To complete the comparison, we express in the same $\Delta \widetilde{\mathrm{P}}$ notation the $\Delta \mathrm{P}_{2}$ performance of the two-dimensional second construct [cf. Eq. (17) and Fig. 3], and obtain

$$
\Delta \widetilde{\mathrm{P}}_{2}=\frac{1}{\mathrm{p}^{3}}\left(\frac{\mathrm{nd}}{\mathrm{y}}\right)^{7 / 2}\left[\frac{\mathrm{H}}{\mathrm{nd}}(\mathrm{p}-1) \mathrm{p}^{6 / 7}+1\right]^{7 / 2} .
$$

The envelope of the constant-p curves derived from Eq. (32) is

$$
\Delta \tilde{\mathrm{P}}_{2} \cong 11.12\left(\mathrm{n} \frac{\mathrm{d}}{\mathrm{y}}\right)^{49 / 26}\left(\frac{\mathrm{H}}{\mathrm{y}}\right)^{21 / 13} .
$$

The $\mathrm{p}$ value along the envelope is described by

$$
\frac{\mathrm{nd}}{\mathrm{H}} \cong \frac{7}{6} \mathrm{p}^{13 / 7} .
$$

Figure 7 shows a comparison between the pressure differ-

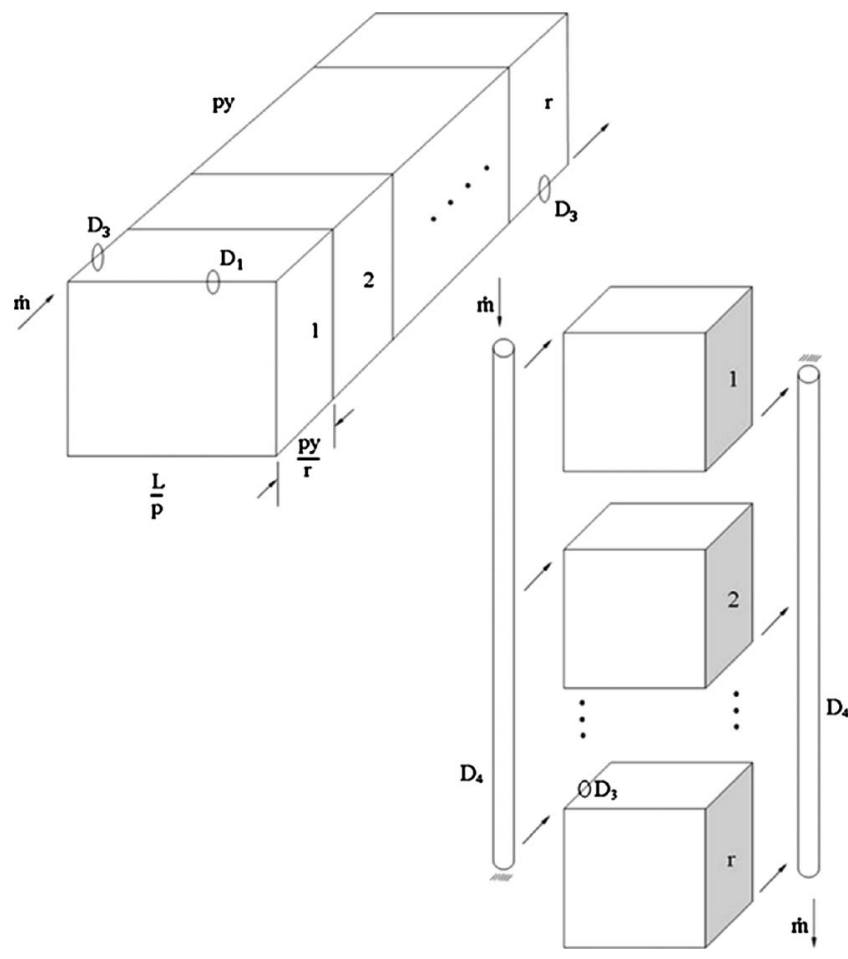

FIG. 8. Fourth construct: the $r$ segments are stacked in the direction perpendicular to the $\mathrm{D}_{3}-\mathrm{D}_{1}$ plane.

ences of the designs of Figs. 1, 3, and 5 for various volume sizes (nd/y). The overall pressure drop of the design of Fig. 1 is greater than in the designs of Figs. 3 and 5. The question next is whether to utilize the design of Fig. 3 or the design of Fig. 5. When $\mathrm{y} / \mathrm{H}>1$, the design of Fig. 5 is recommended; otherwise the design of Fig. 3 is recommended. When $\mathrm{y} / \mathrm{H}$ $=1$, the overall pressure drops of Figs. 3 and 5 are the same.

\section{FOURTH CONSTRUCT}

When the volume of Fig. 5 increases, the length perpendicular to the figure also increases (Fig. 8 top). By cutting Fig. 8 (top) into $r$ equal pieces and stacking them in the direction perpendicular to $D_{3}-D_{1}$ plane, we obtain a new architecture with the dimensions $(\mathrm{rH}) \times(\mathrm{py} / \mathrm{r}) \times(\mathrm{L} / \mathrm{p})$ $=$ LHy, Fig. 8 (bottom). The volume occupied by this fourth construct (Fig. 8, bottom) is same as in the other constructs analyzed until now.

The stream enters this body through one duct of diameter $\mathrm{D}_{4}$ and length $(\mathrm{r}-1) \mathrm{H}$. The stream is then distributed from the $D_{4}$ duct to the $D_{3}$ ducts, after which it follows the same path as in the third construct (Fig. 5). The pressure drop across the fourth construct consists of three terms

$$
\Delta \mathrm{P}_{4}=\frac{2}{3} \mathrm{C}_{\mathrm{t}} \dot{\mathrm{m}}^{2} \frac{(\mathrm{r}-1) \mathrm{H}}{\mathrm{D}_{4}^{5}}+\frac{2}{3} \mathrm{C}_{\mathrm{t}} \frac{\dot{\mathrm{m}}^{2}}{\mathrm{r}^{2}} \frac{\mathrm{py} / \mathrm{r}}{\mathrm{D}_{3}^{5}}+\frac{2}{3} \mathrm{C}_{\mathrm{t}} \frac{\dot{\mathrm{m}}^{2}}{\mathrm{p}^{2}} \frac{\mathrm{L} / \mathrm{p}}{\mathrm{D}_{1}^{5}},
$$

between $\mathrm{p}$ and $\mathrm{n}$ is such that its design falls on the envelope of the curves shown in Fig. 6.

The total flow volume constraint is 


$$
\mathrm{V}=2 \frac{\pi}{4} \mathrm{D}_{4}^{2}(\mathrm{r}-1) \mathrm{H}+2 \mathrm{r} \frac{\pi}{4} \mathrm{D}_{3}^{2} \frac{\mathrm{py}}{\mathrm{r}}+2 \mathrm{p} \frac{\pi}{4} \mathrm{D}_{1}^{2} \frac{\mathrm{L}}{\mathrm{p}} .
$$

We minimized the pressure drop, Eq. (35), with subject to the volume constraint Eq. (36), and obtained the optimal diameter ratios and minimal pressure drop

$$
\begin{aligned}
\frac{\mathrm{D}_{4}}{\mathrm{D}_{3}}= & \mathrm{r}^{3 / 7}, \quad \frac{\mathrm{D}_{4}}{\mathrm{D}_{1}}=\mathrm{p}^{3 / 7}, \quad \frac{\mathrm{D}_{3}}{\mathrm{D}_{1}}=\left(\frac{\mathrm{p}}{\mathrm{r}}\right)^{3 / 7}, \\
\Delta \mathrm{P}_{4}= & \frac{2}{3} \mathrm{C}_{\mathrm{t}} \frac{\dot{\mathrm{m}}^{2} \mathrm{y}^{7 / 2}}{\mathrm{p}^{3} \mathrm{~V}^{5 / 2}}\left(\frac{\pi}{2}\right)^{5 / 2}\left[(\mathrm{r}-1) \frac{\mathrm{H}}{\mathrm{y}}+\mathrm{r}^{-6 / 7} \mathrm{p}\right. \\
& \left.+\mathrm{p}^{-6 / 7} \mathrm{n} \frac{\mathrm{d}}{\mathrm{y}}\right]^{7 / 2} .
\end{aligned}
$$

Nondimensionalizing the pressure drop of Eq. (38) by using Eq. (25), we obtain

$$
\Delta \widetilde{\mathrm{P}}_{4}=\left[(\mathrm{r}-1) \frac{\mathrm{H}}{\mathrm{y}}+\mathrm{r}^{-6 / 7} \mathrm{p}+\mathrm{p}^{-6 / 7} \mathrm{n} \frac{\mathrm{d}}{\mathrm{y}}\right]^{7 / 2} .
$$

One $\Delta \widetilde{\mathrm{P}}_{4}$ curve exists for each $\mathrm{p}$ value. When $\mathrm{p}$ is large, the envelope of this family of curves can be approximated by solving $\partial\left(\Delta \widetilde{\mathrm{P}}_{4}\right) / \partial \mathrm{p}=0$ because the points of intersection on the envelope, $\Delta \widetilde{\mathrm{P}}_{4}(\mathrm{p})=\Delta \widetilde{\mathrm{P}}_{4}(\mathrm{p}+1)$, are approximated by $\Delta \widetilde{\mathrm{P}}_{4}(\mathrm{p})=\Delta \widetilde{\mathrm{P}}_{4}(\mathrm{p}+\mathrm{dp})$. This approximation can then be combined with Eq. (39) to obtain

$$
\begin{aligned}
& \frac{\mathrm{nd}}{\mathrm{y}} \cong \frac{7}{6} \mathrm{r}^{-6 / 7} \mathrm{p}^{13 / 7}, \\
& \Delta \widetilde{\mathrm{P}}_{4}=\left[(\mathrm{r}-1) \frac{\mathrm{H}}{\mathrm{y}}+\frac{13}{6^{6 / 13} 7^{7 / 13}} \mathrm{r}^{-36 / 91}\left(\mathrm{n} \frac{\mathrm{d}}{\mathrm{y}}\right)^{7 / 13}\right]^{7 / 2} .
\end{aligned}
$$

In this analysis, we assumed that each of the $r$ constructs is as shown in Fig. 5, and that its relation between $\mathrm{p}$ and $\mathrm{n}$ is such that its design falls on the envelope of the curves shown in Fig. 6. Equation (39) represents a family of curves in the $\Delta \widetilde{\mathrm{P}}_{4}-\mathrm{nd} / \mathrm{y}$ plane, one curve for each $\mathrm{r}$ and $\mathrm{y} / \mathrm{H}$. Some of the curves for $y / H=1$ and $r=5$ are shown in Fig. 9. The envelope of this family of curves is found by identifying the intersection of two closest curves, $\Delta \widetilde{\mathrm{P}}_{4}(\mathrm{r})=\Delta \widetilde{\mathrm{P}}_{4}(\mathrm{r}+1)$. This yields the relationship between $\mathrm{r}$ and $\mathrm{nd} / \mathrm{y}$ for constant $\mathrm{H} / \mathrm{y}$, in the limit nd/y $\gg 1$,

$$
\mathrm{r}=0.84\left(\frac{\mathrm{y}}{\mathrm{H}}\right)^{91 / 127}\left(\mathrm{n} \frac{\mathrm{d}}{\mathrm{y}}\right)^{49 / 127} .
$$

By substituting Eq. (42) into the Eq. (39), we find the envelope for the fourth construct

$$
\Delta \widetilde{\mathrm{P}}_{4} \cong 45.5\left(\mathrm{n} \frac{\mathrm{d}}{\mathrm{y}}\right)^{343 / 254}\left(\frac{\mathrm{H}}{\mathrm{y}}\right)^{126 / 127} .
$$

In order to compare the design of Fig. 8 with the design of Fig. 5, we set $r=2$, and the optimal diameter ratios and the dimensionless pressure drop for the fourth construct become

$$
\frac{D_{4}}{D_{3}}=2^{3 / 7}, \quad \frac{D_{4}}{D_{1}}=p^{3 / 7}, \quad \frac{D_{3}}{D_{1}}=\left(\frac{p}{2}\right)^{3 / 7}
$$
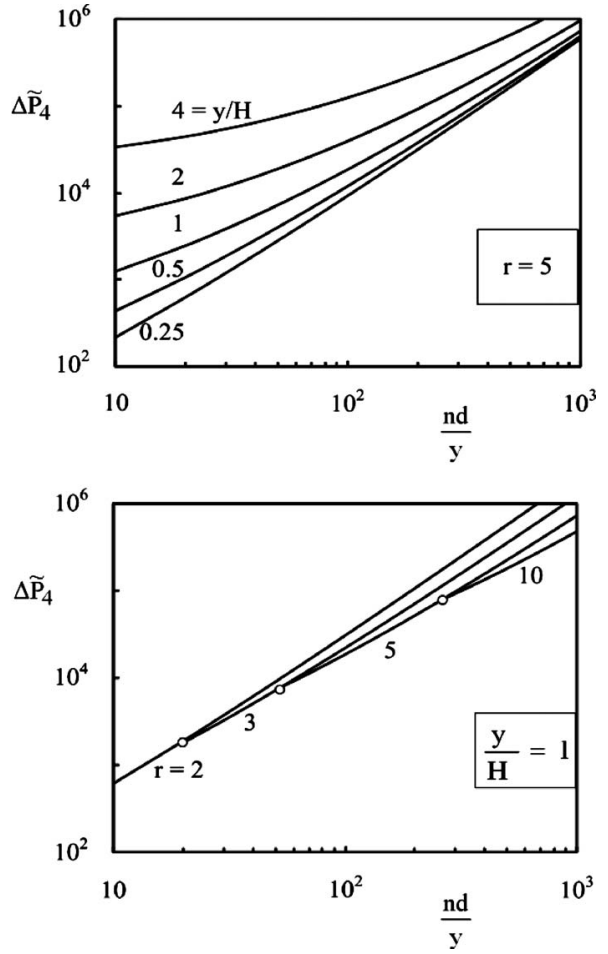

FIG. 9. The performance curves of the designs of Fig. 8.

$$
\Delta \widetilde{P}_{4}=\left[\frac{\mathrm{H}}{\mathrm{y}}+2^{-6 / 7} \mathrm{p}+\mathrm{p}^{-6 / 7} \mathrm{n} \frac{\mathrm{d}}{\mathrm{y}}\right]^{7 / 2} .
$$

Substituting $r=2$ in Eq. (40) and eliminating p between Eqs. (40) and (45), we find

$$
\Delta \widetilde{\mathrm{P}}_{4} \cong 4.29\left(\mathrm{n} \frac{\mathrm{d}}{\mathrm{y}}\right)^{49 / 26} \text {. }
$$

The significance of the Eq. (46) becomes clear when we compare it with the Eq. (31),

$$
\frac{\Delta \widetilde{\mathrm{P}}_{4}(\mathrm{r}=2, \text { envelope })}{\Delta \widetilde{\mathrm{P}}_{4}(\text { envelope })} \cong 0.44 \text {. }
$$

When $\mathrm{p}$ is large enough so that the approximation $\Delta \widetilde{\mathrm{P}}_{4}(\mathrm{p})$ $=\Delta \widetilde{\mathrm{P}}_{4}(\mathrm{p}+\mathrm{dp})$ is adequate, Eq. (47) shows that the fourth construct is preferable. Its overall pressure drop is less than half of the pressure drop of the design of Fig. 5. This is shown in Fig. 10. Equations (40) and (42) yield the relation between $p$ and $\mathrm{r}$ for the best designs (on the envelope) of Fig. 8,

$$
\mathrm{p} \cong 1.2 \frac{\mathrm{H}}{\mathrm{y}} \mathrm{r}^{169 / 91}
$$

The $\mathrm{p}$ and $\mathrm{r}$ values must be integers, and, therefore, Eq. (48) is approximate.

Figure 11 is a generalization of Fig. 10 by utilizing various $\mathrm{r}$ values. The curves for $\Delta \widetilde{\mathrm{P}}_{1}, \Delta \widetilde{\mathrm{P}}_{3}$, and $\Delta \widetilde{\mathrm{P}}_{4}$ intersect and generate a piecewise linear curve with the slope decreasing toward larger volumes nd/y. The "transitions" from one design to the next are located as follows: 


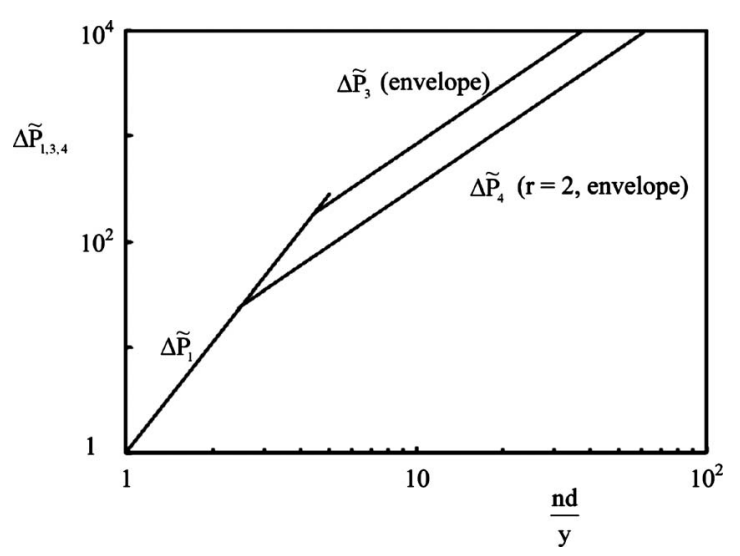

FIG. 10. The transition points between the designs of Figs. 1, 5, and 8.

$$
\begin{aligned}
\mathrm{nd} / \mathrm{y}= & 4.38, \quad \text { from } \Delta \tilde{\mathrm{P}}_{1} \text { to } \Delta \widetilde{\mathrm{P}}_{3}(\mathrm{p}=2) \\
& \text { and } \Delta \widetilde{\mathrm{P}}_{4}(\mathrm{r}=4, \mathrm{p}=12, \mathrm{y} / \mathrm{H}=2), \\
\mathrm{nd} / \mathrm{y}= & 13.98, \quad \text { from } \Delta \widetilde{\mathrm{P}}_{3}(\mathrm{p}=4) \\
& \text { to } \Delta \widetilde{\mathrm{P}}_{4}(\mathrm{r}=4, \mathrm{p}=24, \mathrm{y} / \mathrm{H}=1), \\
\mathrm{nd} / \mathrm{y}= & 50.64, \quad \text { from } \Delta \widetilde{\mathrm{P}}_{3}(\mathrm{p}=8) \\
& \text { to } \Delta \widetilde{\mathrm{P}}_{4} \quad(\mathrm{r}=5, \mathrm{p}=75, \mathrm{y} / \mathrm{H}=0.5)
\end{aligned}
$$

The lowest $\Delta \widetilde{\mathrm{P}}$ values which can be obtained with the fourth construct, Fig. 8, increase proportionally with nd/y raised to the power $343 / 254=1.35$. This increase is slower than along the $\Delta \widetilde{\mathrm{P}}_{3}$ envelope, where the volume size $(\mathrm{nd} / \mathrm{y})$ is raised to the power $49 / 26=1.88$.

The $\Delta \widetilde{\mathrm{P}}_{2}$ and $\Delta \widetilde{\mathrm{P}}_{4}$ curves are drawn in Fig. 12 in order to compare the design of Fig. 8 and the design of Fig. 3. When nd/y is efficiently large, the design of Fig. 8 is better. Comparing Figs. 11 and 12 we see that the design of Fig. 3 is better than the design of Fig. $5\left(\Delta \widetilde{\mathrm{P}}_{3}\right)$ because it offers less pressure drop $\left(\Delta \widetilde{\mathrm{P}}_{2}\right)$ in large $\mathrm{y} / \mathrm{H}$ ratios. However, in order to bathe every point of the volume, the design of Fig. 3 requires small $\mathrm{y} / \mathrm{H}$ ratios. This requirement is in conflict with the

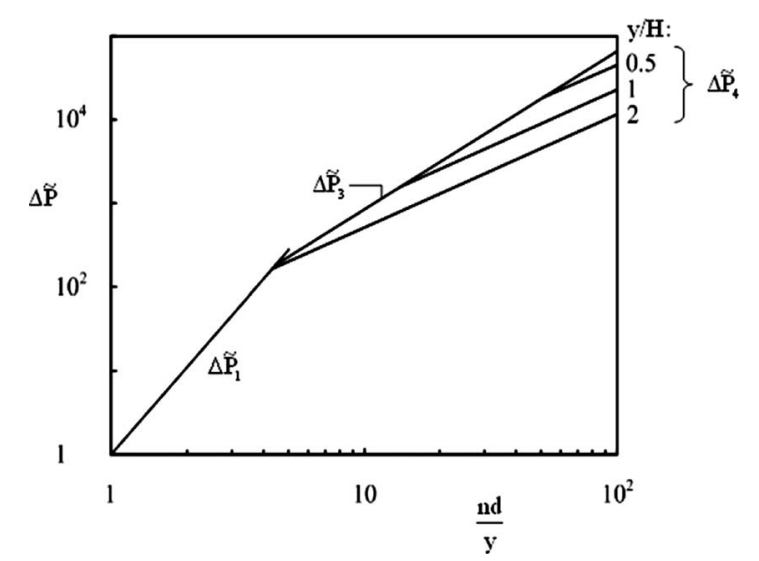

FIG. 11. The reduction in global flow resistance by changing the design from Figs. 1-5 and 8.

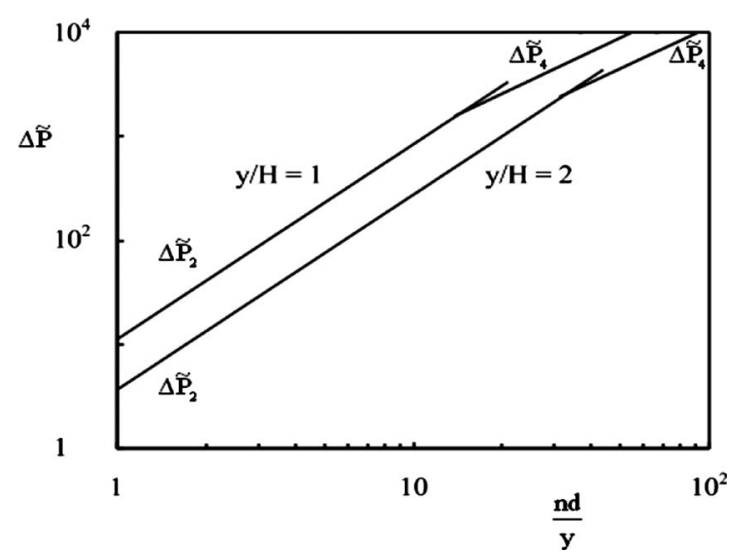

FIG. 12. The reduction in global flow resistance by changing the design from Fig. 3-8.

previous observation, and, therefore, the design of Fig. 5 is preferable in a wider volume size (nd/y) range than the design of Fig. 3.

\section{SCALING UP: THE EFFECT OF SIZE ON DESIGN (CONFIGURATION)}

Putting all these constructs and results together, we uncover a very important feature of the vascular design. As the volume size increases, new architectures (with stepwise greater complexity) replace the existing architectures. We see this in how the exponent of size (nd/y) in the $\Delta \mathrm{P}$ formulas decreases from one design to the next-Figs. 1, 5, and 8 .

A bird's eye view of how the global $\Delta \mathrm{P}$ is reduced by switching from one design to the next is shown in Fig. 13. Here we used the $\Delta \mathrm{P}_{1}$ formula of Fig. 1 as reference [Eq. (12)], and plotted the relative size of the pressure drop of subsequent designs, Figs. 5 and 8 . We see significant reductions in $\Delta \mathrm{P} / \Delta \mathrm{P}_{1}$ as the configuration changes in the direction of larger volume sizes. The decreases in $\Delta \mathrm{P} / \Delta \mathrm{P}_{1}$ accelerate as the volume increases.

Figure 13 was drawn based on the assumption of the volume elements are cubes with the side, $\mathrm{L}_{0}$. This means that $\mathrm{d}$, $\mathrm{y}$, and $\mathrm{H}$ are equal to $\mathrm{L}_{0}$, and that the pressure drops of the design of Figs. 1, 5, and 8 depend only on n, which represents the abscissa in Fig. 13.

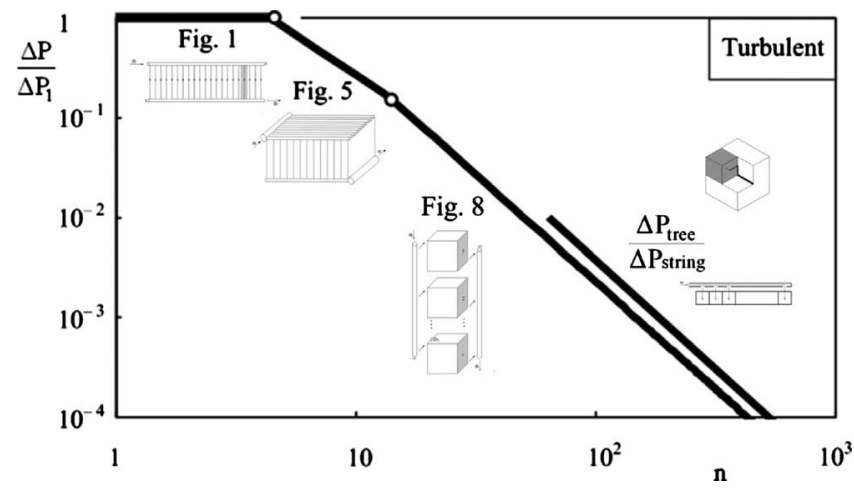

FIG. 13. Turbulent flow: the pressure drop of the designs of Figs. 1, 5, and 8 divided by the pressure drop of the design of Fig. 1, and the pressure drop of the tree network design of Fig. 15 divided by the pressure drop of the string design of Fig. 16. 


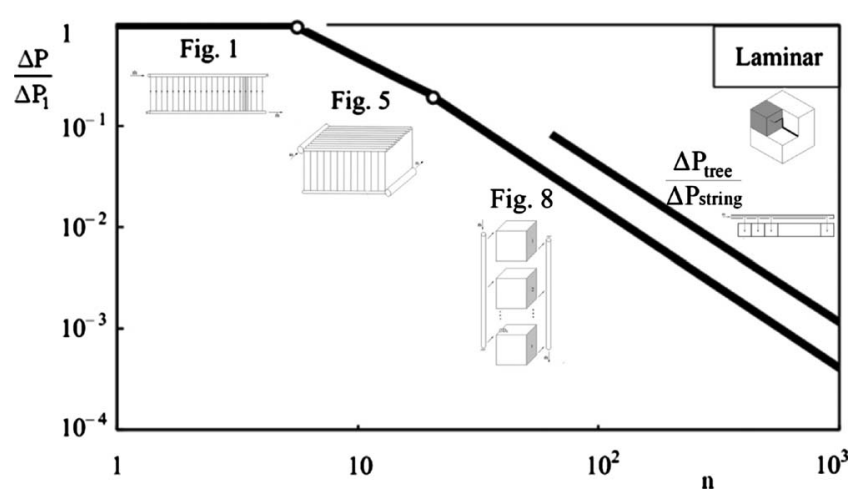

FIG. 14. Laminar flow: the pressure drop of the designs of Figs. 1, 5, and 8 divided by the pressure drop of the design of Fig. 1, and the pressure drop of the tree network design of Fig. 15 divided by the pressure drop of the string design of Fig. 16.

We investigated the same phenomenon in the case of laminar flow, for which the $\Delta \mathrm{P}$ formulas are reported in Kim et al. ${ }^{31}$ This is shown in Fig. 14, and the trend is qualitatively the same as for turbulent flow but not as steep. Comparing Figs. 13 and 14 we conclude that the act of switching from one design to the next is more beneficial when the flow is turbulent.

The effect of size is also deducible by analyzing the tree flow structure shown in Fig. 15. The volume contains $n$ $=2^{\mathrm{m}}$ volume elements of size $\mathrm{L}_{0}^{3}$, each element being bathed by one tube of length $\mathrm{L}_{0}$, diameter $\mathrm{D}_{0}$, and the flow rate $\dot{\mathrm{m}}_{0}$. The tubes are joined (paired) into larger tubes, and the number of pairing level is $\mathrm{m}$. The total flow rate that bathes the $\mathrm{nL}_{0}^{3}$ volume is $\dot{\mathrm{m}}=2^{\mathrm{m}} \dot{\mathrm{m}}_{0}$.

At each pairing junction, the tube diameter increases by the factor $2^{3 / 7}$, which is the optimal factor for turbulent flow. ${ }^{1}$ To increase the size of the volume by a factor of 2 in $\mathrm{m}$ (e.g., from $m=3$ to $m=6$, Fig. 15), the tube lengths must increase by an average factor of $2^{1 / 3}$ during each pairing. The pressure drop along one tube (i) is $\Delta \mathrm{P}=(1 / 3) \mathrm{C}_{\mathrm{t}} \dot{\mathrm{m}}_{\mathrm{i}}^{2} \mathrm{~L}_{\mathrm{i}} / \mathrm{D}_{\mathrm{i}}^{5}$, therefore, the pressure drop along the entire structure of Fig. 15 is (this, after the observation that in order for the global $\Delta \mathrm{P}$ to be minimal the $\Delta$ Ps must be distributed uniformly along all the pairing levels ${ }^{2}$ ),

$$
\Delta \mathrm{P}=\frac{1}{3} \mathrm{C}_{\mathrm{t}} \dot{\mathrm{m}}_{0}^{2} \frac{\mathrm{L}_{0}}{\mathrm{D}_{0}^{5}}(\mathrm{~m}+1) .
$$

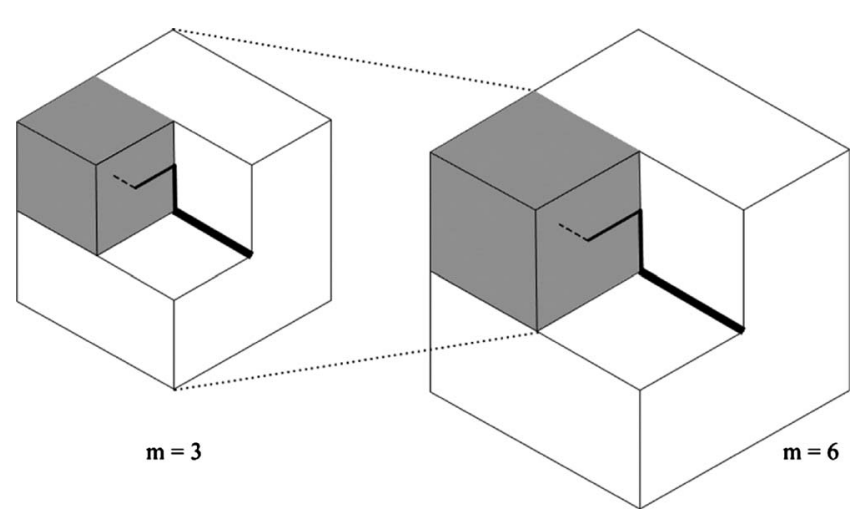

FIG. 15. Vascular volume bathed by a tree-shaped flow generated by pairing smaller ducts into larger ducts.

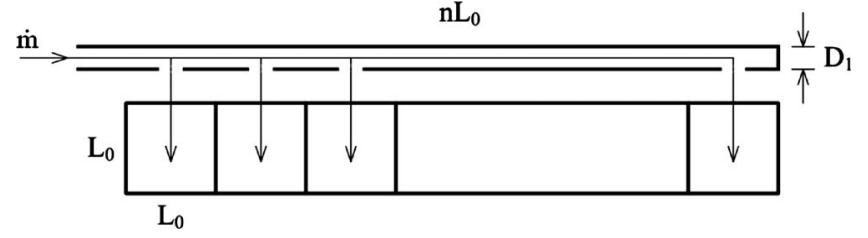

FIG. 16. Elemental volumes of size $\mathrm{L}_{0}^{3}$ arranged as a string and bathed by a single stream.

The total duct volume V of the design of Fig. 15 is

$$
\mathrm{V}=2^{\mathrm{m}} \frac{\pi}{4} \mathrm{D}_{0}^{2} \mathrm{~L}_{0}\left(\sum_{\mathrm{j}=0}^{\mathrm{m}} 2^{4 \mathrm{j} / 21}\right) \text {. }
$$

Next, we combine Eqs. (49) and (50) with $\dot{\mathrm{m}}=2^{\mathrm{m}} \dot{\mathrm{m}}_{0}$, and eliminate $\mathrm{D}_{0}$,

$$
(\Delta \mathrm{P})_{\text {tree }}=\frac{1}{3} \mathrm{C}_{\mathrm{t}} \dot{\mathrm{m}}^{2}\left(\frac{\pi}{4}\right)^{5 / 2} \frac{\mathrm{L}_{0}^{7 / 2}}{\mathrm{~V}^{5 / 2}} 2^{\mathrm{m} / 2}(\mathrm{~m}+1)\left(\sum_{\mathrm{j}=0}^{\mathrm{m}} 2^{4 \mathrm{j} / 21}\right)^{5 / 2} .
$$

To conduct a comparison of the curves of shown in Fig. 13 for the designs of Figs. 1, 5, and 8, we compare the design of Fig. 15 with one that relies on the design shown in Fig. 1.

Consider then the string design shown in Fig. 16. The $n$ elemental volumes are supplied (or cleansed) by a single stream flowing through a tube of length $\mathrm{nL}_{0}$ and diameter $\mathrm{D}_{1}$. Because the stream $\dot{m}$ is distributed uniformly to the string of $\mathrm{n}$ elements, the flow rate $\dot{m}$ decreases linearly along the $D_{1}$ tube. The pressure drop of the design of Fig. 16 is

$$
(\Delta \mathrm{P})_{\text {string }}=\frac{1}{3} \mathrm{C}_{\mathrm{t}} \dot{\mathrm{m}}^{2}\left(\frac{\pi}{4}\right)^{5 / 2} \frac{\mathrm{L}_{0}^{7 / 2}}{\mathrm{~V}^{5 / 2}} 2^{7} \mathrm{~m} / 2
$$

Dividing Eq. (51) by Eq. (52), we discover the relation between the pressure drops of Figs. 15 and 16,

$$
\frac{\Delta \mathrm{P}_{\text {tree }}}{\Delta \mathrm{P}_{\text {string }}}=2^{-3 \mathrm{~m}}(\mathrm{~m}+1)\left(\sum_{\mathrm{j}=0}^{\mathrm{m}} 2^{4 \mathrm{j} / 21}\right)^{5 / 2} \text {. }
$$

Even though the $\Delta \mathrm{P}_{\text {tree }} / \Delta \mathrm{P}_{\text {string }}$ curves were simpler to derive, they approach fairly closely the stepwise linear curves derived earlier and plotted in Figs. 13 and 14.

\section{CONCLUSIONS}

In this paper, we showed how to determine the flow configuration that offers most effective volumetric bathing for a finite volume. The fluid enters the volume as one stream through a large vessel, and exits the volume through another large vessel. In between, the fluid bathes every volume element such as: we show that this is achievable when the flow architecture is configured as two trees that touch canopy to canopy. Every volume element is reached by branches of both trees.

The fundamental discovery is that the tree-tree architecture must emerge and change abruptly as the volume size increases. This was not known before hand, i.e., at the start of the search for the flow configuration with least global flow resistance. In this study we showed this stepwise evolution with four designs, each optimized to be the best that it can be 
when its total volume and total flow volume are fixed. Generally, the global flow resistance of the vascular volume increases with the size of the volume but this increase decreases when the design switches from one to the next more complex design (e.g., Fig. 13).

The route to better and better flow design is the proper selection of the vascular design of one type, and one level of complexity for a given volume size. In every case, the complexity is finite (modest) and optimized. Complexity is one of the properties of the emerging design. It is not something to be maximized in the hope of better flow performance.

The practical importance of the design emergence phenomenon unveiled in this paper is twofold. First, this work shows that natural vascular designs emerge as animate (e.g., lungs vascular tissues) and inanimate systems (river basins deltas) in order to facilitate the movement of mass volumetrically (point-volume, volume-point, point-area, area-point). Second, this work shows the one to relationship between size and vascular complexity. The larger vascular bodies must be more complex in order to achieve the easiest flow. This second contribution of this paper is the key to practicing correctly the work of scaling up and scaling down in engineering designs. To design a larger life size in terms of not to magnify (to blow up) a smaller laboratory design, the large design must have its own characteristic ( $\mathrm{p}$ each table) architecture which is now documented in the article.

\section{ACKNOWLEDGMENTS}

This work was supported by the Republic of Turkey and the U.S. National Science Foundation.

${ }^{1}$ A. Bejan and S. Lorente, Design with Constructal Theory (Wiley, Hoboken, 2008).

${ }^{2}$ A. Bejan and S. Lorente, Philos. Trans. R. Soc. London, Ser. B 365, 1335 (2010).

${ }^{3}$ A. H. Reis, Appl. Mech. Rev. 59, 269 (2006).
${ }^{4}$ V. A. P. Raja, T. Basak, and S. K. Das, Int. J. Heat Mass Transfer 51, 3582 (2008).

${ }^{5}$ S. Lorente, J. Phys. D 40, 2941 (2007).

${ }^{6}$ Y. Chen and P. Cheng, Int. Commun. Heat Mass Transfer 32, 931 (2005).

${ }^{7}$ A. Y. Alharbi, D. V. Pence, and R. N. Cullion, ASME J. Fluids Eng. 125, 1051 (2003).

${ }^{8}$ A. H. Reis, Geomorphology 78, 201 (2006).

${ }^{9}$ Y. S. Muzychka, Int. J. Therm. Sci. 46, 245 (2007).

${ }^{10}$ A. H. Reis, A. F. Miguel, and M. Aydin, Med. Phys. 31, 1135 (2004).

${ }^{11}$ Y. Azoumah, N. Mazet, and P. Neveu, Int. J. Heat Mass Transfer 47, 2961 (2004).

${ }^{12}$ D. Tondeur and L. Luo, Chem. Eng. Sci. 59, 1799 (2004).

${ }^{13}$ A. F. Miguel, J. Theor. Biol. 242, 954 (2006).

${ }^{14}$ S. Zhou, L. Chen, and F. Sun, Energy Convers. Manage. 48, 106 (2007).

${ }^{15}$ W. Wechsatol, J. C. Ordonez, and S. Kosaraju, J. Appl. Phys. 100, 113514 (2006).

${ }^{16}$ W. Wu, L. Chen, and F. Sun, Energy Convers. Manage. 48, 101 (2007).

${ }^{17}$ L. A. O. Rocha, E. Lorenzini, and C. Biserni, Int. Commun. Heat Mass Transfer 32, 1281 (2005).

${ }^{18}$ W. Wu, L. Chen, and F. Sun, Appl. Energy 84, 39 (2007).

${ }^{19}$ L. Luo and D. Tondeur, China Particuol. 3, 329 (2005).

${ }^{20}$ A. Beyene and J. Peffley, J. Energy Eng. 135, 112 (2009).

${ }^{21}$ P. Xu, B. Yu, S. Qiu, and J. Cai, Physica A 387, 6471 (2008).

${ }^{22}$ X.-Q. Wang, A. S. Mujumdar, and C. Yap, J. Electron. Packag. 128, 38 (2006).

${ }^{23}$ G. Lorenzini and L. A. O. Rocha, Int. J. Heat Mass Transfer 52, 1458 (2009).

${ }^{24}$ C. Biserni, L. A. O. Rocha, G. Stanescu, and E. Lorenzini, Int. J. Heat Mass Transfer 50, 2132 (2007).

${ }^{25}$ G. Lorenzini and L. A. O. Rocha, Int. J. Heat Mass Transfer 49, 4552 (2006).

${ }^{26}$ Y. Azoumah, P. Neveu, and N. Mazet, AIChE J. 53, 1257 (2007).

${ }^{27}$ S. Zhou, L. Chen, and F. Sun, J. Phys. D 40, 3545 (2007).

${ }^{28}$ A. H. Reis and A. F. Miguel, Thermal Sci. 10, 57 (2006).

${ }^{29}$ A.-H. Wang, X.-G. Liang, and J.-X. Ren, Int. J. Thermophys. 27, 126 (2006).

${ }^{30}$ M. J. Carone, C. B. Williams, J. K. Allen, and F. Mistree, ASME 2003 Design Engineering Technical Conferences and Computer and Information in Engineering Conference, Vol. 3b, 15th International Conference on Design Theory and Methodology, Chicago, Illinois USA, 2-6 September 2003, pp. 719-730.

${ }^{31}$ S. Kim, S. Lorente, A. Bejan, W. Miller, and J. Morse, J. Appl. Phys. 103, 123511 (2008) 